\title{
Extracranial meningioma as an incidental infratemporal fossa mass in a patient presenting with a history of traumatic brain injury
}

\author{
Yolanda M Mendoza, ${ }^{1}$ Richard M Buck (1) , Brian M Boldt ${ }^{1,2}$
}

'Department of Radiology, Madigan Army Medical Center, Tacoma, Washington, USA 2Department of Radiology, School of Medicine, Uniformed Services University of the Health Sciences, Bethesda, Maryland, USA

Correspondence to Dr Yolanda M Mendoza; yolanda.m.mendoza3.mil@ mail.mil

Accepted 14 May 2020
Check for updates

(C) BMJ Publishing Group Limited 2020. No commercial re-use. See rights and permissions. Published by BMJ.

To cite: Mendoza YM,
Buck RM, Boldt BM. BMJ
Case Rep 2020;13:e236298.
doi:10.1136/bcr-2020-
236298

\section{DESCRIPTION}

A 28-year-old man presented to his primary care physician for chronic headaches, memory concerns and a history of traumatic brain injury. A non-contrast brain MRI was performed, which revealed a large T2 hyperintense, lobulated mass in the left infratemporal fossa. The lesion had an intracranial origin involving the left cavernous sinus and middle cranial fossa with extracranial extension through the foramen rotundum and inferior orbital fissure, causing mild

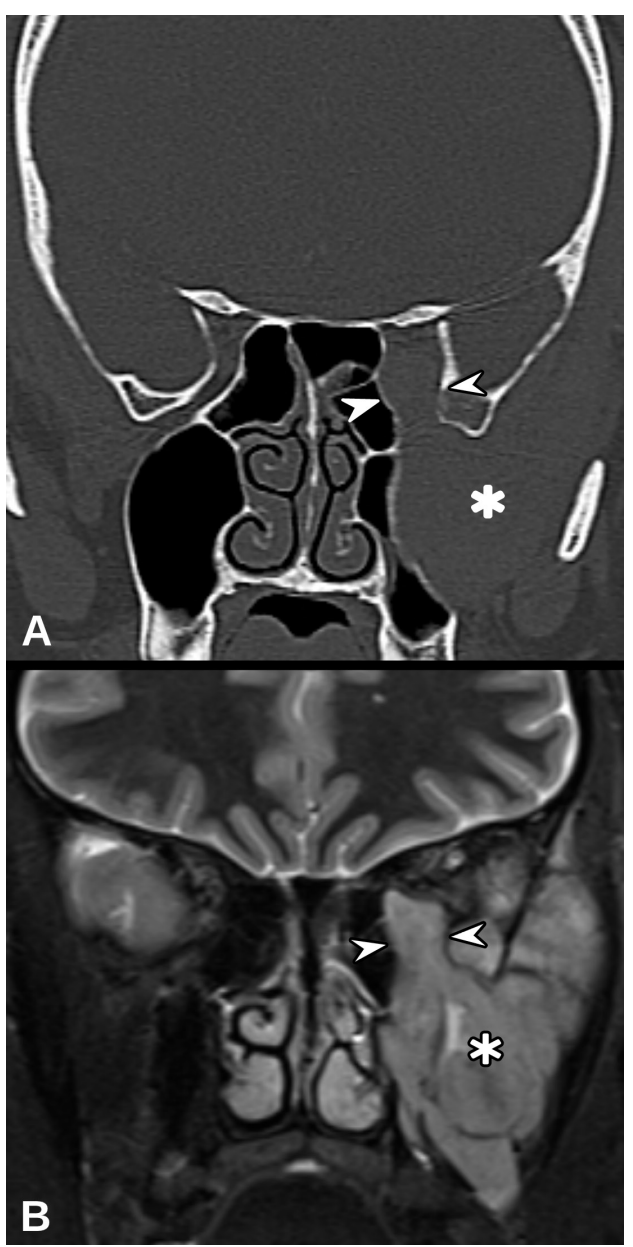

Figure 1 Coronal CT (A) and short tau inversion recovery (STIR) (B) images demonstrate a large lobulated hyperintense mass (asterisk) extending through the inferior orbital fissure (arrowheads) into the left infratemporal fossa and masticator space. Note the smooth expansion of the inferior orbital fissure and preservation of the cortical bone, compatible with a nonaggressive process.

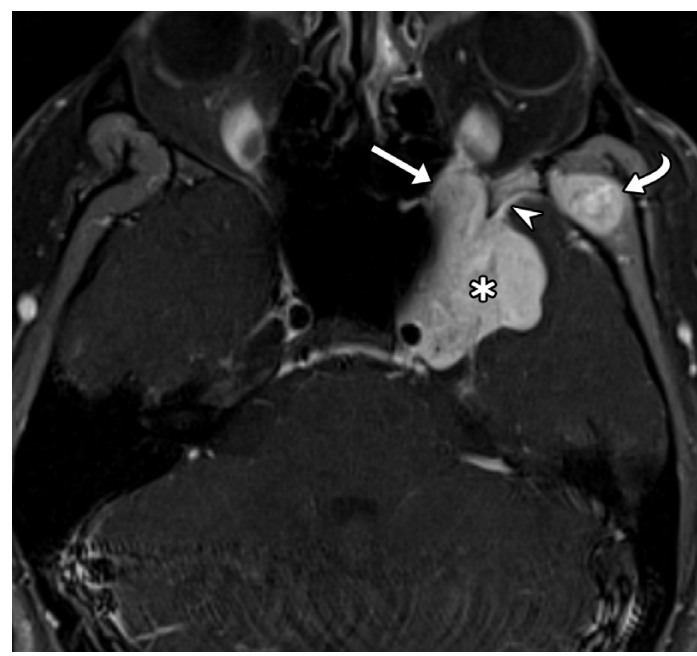

Figure 2 Axial post-contrast T1 weighted MR image demonstrates a dural-based attachment (arrowhead), along with smooth expansion of the left foramen rotundum and inferior orbital fissure (arrow); note the intracranial component within the middle cranial fossa (asterisk) and the extra-cranial component lateral to the lateral orbital wall (curved arrow).

mass effect on the adjacent brain and muscles of mastication without oedema (figure 1). Given the trans-spatial location with extension through the skull base foramen, the differential diagnosis included nerve sheath tumour, venolymphatic malformation, meningioma and less likely malignant tumour. The patient was referred to ear, nose and throat (ENT), and contrast-enhanced MRI of the skull base and CT neck were recommended for further evaluation.

Evaluation by ENT revealed a history of left facial and palatal numbness in a V2 distribution, and physical examination demonstrated diminished sensation in the left V2 distribution. CT neck showed smooth benign-appearing expansion of the foramen rotundum without destructive bony changes. MRI with contrast demonstrated an intracranial lesion involving the central skull base with a dural-based attachment and extension through the foramen rotundum into the infratemporal fossa (figure 2). Given the combination of benign imaging features and an intracranial duralbased attachment, a secondary extracranial meningioma was favoured.

The patient underwent a CT-guided percutaneous biopsy, confirming meningioma. He was subsequently referred to an outside hospital for higher level subspecialty care, where he underwent preoperative tumour 
angioembolisation and craniotomy with subtotal tumour resection, for which he completed 6 weeks of radiation therapy. Follow-up physical examination and imaging after completion of radiation therapy demonstrated persistent but improved diminished sensation in the left V2 distribution with residual tumour along the left middle cranial fossa, sphenoid wing and cavernous sinus. The patient will be followed with serial surveillance MRI to monitor response to therapy.

Although meningiomas are relatively common, only $2 \%$ of meningiomas are extracranial. ${ }^{1}{ }^{2}$ In comparison to intracranial meningiomas, extracranial meningiomas disproportionately affect male patients. ${ }^{12}$ Extracranial meningiomas can be categorised as primary tumours which are completely extracranial without an associated intracranial mass, or secondary tumours which are a propagation of an intracranial meningioma. ${ }^{1}$ Common locations include the orbit, nasal cavity and infratemporal fossa. ${ }^{2}$ Clinical presentation is varied with symptoms relating to the specific anatomical site involved, for example, nasal cavity location with the symptom of epistaxis. ${ }^{3}$ Treatment is primarily surgical resection; however, radiation therapy may be used as an adjunct, particularly in cases of incomplete resection. ${ }^{4}$ Our patient presented with relatively non-specific symptoms and was found to have an incidental infratemporal fossa mass confirmed to be an extracranial meningioma.

\section{Patient's perspective}

I had a history of traumatic brain injury and was experiencing chronic headaches for several years. I was told that they were migraines, but they just would not go away. When I found out I had this brain mass, it was somewhat of a relief to know that there was something actually responsible for my long-standing headaches and other symptoms. It has been a long up and down road to recovery following surgery and treatment, and I am ready for this to be over so I can get back to work!

\section{Learning points}

- Extracranial meningiomas are rare tumours that can present as a primary extracranial mass or as an extension of an intracranial meningioma into the head and neck and should be considered in patients presenting with atypical or no symptoms, as well as findings of an extracranial mass involving the skull base.

- Contrast-enhanced MRI is the imaging modality of choice, and an intracranial dural attachment is characteristic.

- Treatment is surgical resection, although radiation therapy is used as an adjunct in cases of incomplete resection.

Contributors YMM: drafting of the manuscript, editing and revision of the final manuscript. RMB: editing and revision of the final manuscript, acquisition of images. BMB: critical revision for important intellectual content, selection of images and revision of final manuscript.

Funding The authors have not declared a specific grant for this research from any funding agency in the public, commercial or not-for-profit sectors.

Competing interests None declared.

Patient consent for publication Obtained.

Provenance and peer review Not commissioned; externally peer reviewed.

\section{ORCID iD}

Richard M Buck http://orcid.org/0000-0003-4420-2969

\section{REFERENCES}

1 Albsoul N, Rawashdeh B, Albsoul A, et al. A rare case of extracranial meningioma in parapharyngeal space presented as a neck mass. Int J Surg Case Rep 2015;11:40-3.

2 Krasic D, Stojanovic M, Petrovic V, et al. Extracranial meningiomas in the head-and-neck region: a 15 years' experience. Niger J Clin Pract 2018;21:1078-80.

3 Rushing EJ, Bouffard J-P, McCall S, et al. Primary extracranial meningiomas: an analysis of 146 cases. Head Neck Pathol 2009;3:116-30.

4 Minniti G, Amichetti M, Enrici RM. Radiotherapy and radiosurgery for benign skull base meningiomas. Radiat Oncol 2009;4:42.

Copyright 2020 BMJ Publishing Group. All rights reserved. For permission to reuse any of this content visit

https://www.bmj.com/company/products-services/rights-and-licensing/permissions/

BMJ Case Report Fellows may re-use this article for personal use and teaching without any further permission.

Become a Fellow of BMJ Case Reports today and you can:

- Submit as many cases as you like

- Enjoy fast sympathetic peer review and rapid publication of accepted articles

- Access all the published articles

- Re-use any of the published material for personal use and teaching without further permission

Customer Service

If you have any further queries about your subscription, please contact our customer services team on +44 (0) 2071111105 or via email at support@bmj.com.

Visit casereports.bmj.com for more articles like this and to become a Fellow 